\title{
A Dual-Band Antenna for RF Energy Harvesting Systems in Wireless Sensor Networks
}

\author{
A. Bakkali, ${ }^{1,2}$ J. Pelegri-Sebastia, ${ }^{2}$ T. Sogorb, ${ }^{2}$ V. Llario, ${ }^{2}$ and A. Bou-Escriva ${ }^{2}$ \\ ${ }^{1}$ Laboratory of Innovative Technologies, Abdelmalek Essaadi University, Tangier, Morocco \\ ${ }^{2}$ Research Institute for Integrated Management of Coastal Areas, Universitat Politècnica of Valencia, Grao de Gandia, \\ 46730 Valencia, Spain \\ Correspondence should be addressed to J. Pelegri-Sebastia; jpelegri@upv.es
}

Received 29 September 2015; Revised 9 December 2015; Accepted 13 December 2015

Academic Editor: Giorgio Pennazza

Copyright (C) 2016 A. Bakkali et al. This is an open access article distributed under the Creative Commons Attribution License, which permits unrestricted use, distribution, and reproduction in any medium, provided the original work is properly cited.

In this paper, we focus on ambient radio frequency energy available from commercial broadcasting stations in order to provide a system based on RF energy harvesting using a new design of receiving antenna. Several antenna designs have been proposed for use in RF energy harvesting systems, as a pertinent receiving antenna design is highly required since the antenna features can affect the amount of energy harvested. The proposed antenna is aimed at greatly increasing the energy harvesting efficiency over Wi-Fi bands: $2.45 \mathrm{GHz}$ and $5 \mathrm{GHz}$. This provides a promising alternative energy source in order to power sensors located in harsh environments or remote places, where other energy sources are impracticable. The dual-band antenna can be easily integrated with RF energy harvesting system on the same circuit board. Simulations and measurements were carried out to evaluate the antenna performances and investigate the effects of different design parameters on the antenna performance. The receiving antenna meets the required bandwidth specification and provides peak gain of more than $4 \mathrm{dBi}$ across the operating band.

\section{Introduction}

The use of renewable energies to power electronics devices is not a new concept. The process of extracting energy from the ambient environment to generate electricity is termed as energy harvesting or energy scavenging $[1,2]$. This energy can be harvested from various sources available in the ambient environment such as thermal energy [3,4], mechanical energy [5], and radiant energy [6, 7]. In Table 1, properties of widely utilized ambient energy sources are introduced.

Among the available ambient energy sources, RF energy has greatly grown due to the preponderance of wireless signals, such as mobile base stations [8] and Wi-Fi networks [9], radio and TV transmitters [10-12], and microwave radios and mobile phones [13]. Compared to the other energy sources, RF energy provides a relatively low energy density of $0.2 \mathrm{nW} / \mathrm{cm}^{2}-1 \mu \mathrm{W} / \mathrm{cm}^{2}$. Energy harvesters for low power devices, including applications related to wireless sensor networks (WSNs), extend significantly the operating lifetime and present a new challenge as the harvesting system has to be comparable in size with sensor nodes. This technique could be especially useful for powering up the wireless networks deployed in harsh environment, charging batteries, or storing energy in super capacitors. In this paper, we focus on ambient $\mathrm{RF}$ energy harvesting technology that will have an important potential to impact sensors located in harsh environments or remote places, where other energy sources as wind or solar sources are impracticable. This technique attracted significant attention and multiple RF energy harvesting systems including receiving antennas, matching circuits, and rectifying circuits which have been developed for green supply of low consumption electronics $[14,15]$. The general structure of a typical RF energy harvester is shown in Figure 1, comprised of receiving antenna along with a circuit capable of converting RF signals into DC voltage. The antenna picks up the RF power sent out by the network controller, the impedance matching network ensures maximum power transfer in the system, and the rectifier converts the RF power to a DC voltage.

The components of the energy harvesting system (antenna, matching network, and rectifier) are usually known as a Rectenna or a RF/DC, which is able to harvest 


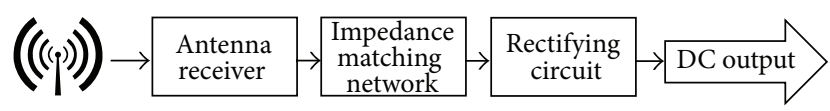

FIGURE 1: Block diagram of RF energy harvesting system.

TABLE 1: Characteristics of various energy sources and harvested power.

\begin{tabular}{lcc}
\hline Source & Source power & Harvested power \\
\hline Ambient light & & \\
Indoor & $0.1 \mathrm{~mW} / \mathrm{cm}^{2}$ & $10 \mu \mathrm{W} / \mathrm{cm}^{2}$ \\
Outdoor & $100 \mathrm{~mW} / \mathrm{cm}^{2}$ & $10 \mathrm{~mW} / \mathrm{cm}^{2}$ \\
Vibration & & \\
$\quad$ Human & $0.5 \mathrm{~m} @ 1 \mathrm{~Hz} 1 \mathrm{~m} / \mathrm{s}^{2} @ 50 \mathrm{~Hz}$ & $4 \mu \mathrm{W} / \mathrm{cm}^{2}$ \\
$\quad$ Industrial & $1 \mathrm{~m} @ 5 \mathrm{~Hz} 10 \mathrm{~m} / \mathrm{s}^{2} @ 1 \mathrm{kHz}$ & $100 \mu \mathrm{W} / \mathrm{cm}^{2}$ \\
Thermal energy & & \\
$\quad$ Human & $20 \mathrm{~mW} / \mathrm{cm}^{2}$ & $30 \mu \mathrm{W} / \mathrm{cm}^{2}$ \\
$\quad$ Industrial & $100 \mathrm{~mW} / \mathrm{cm}^{2}$ & $1-10 \mathrm{~mW} / \mathrm{cm}^{2}$ \\
RF & & \\
Cell phone & $0.3 \mu \mathrm{W} / \mathrm{cm}^{2}$ & $0.1 \mu \mathrm{W} / \mathrm{cm}^{2}$ \\
\hline
\end{tabular}

high-frequency energy in free space and convert it to DC power. Harvesting ambient RF energy and converting the harvested power to useful DC power require a careful design:

(i) An efficient antenna for maximizing the reception of the ambient RF signals.

(ii) A matching network to match the antenna impedance with the complex load impedance, composed of inductive and capacitive elements, in order to achieve the maximum power delivery from antenna to rectifier.

(iii) Optimization of the rectifier circuit for RF to DC conversion.

In literature numerous research works have been reported on ambient RF energy harvesting systems. The authors in [16] presented an optimized wireless energy harvester for an UHF digital TV signal. The power harvested at distance of over $6.3 \mathrm{~km}$ from the TV broadcast source is successfully used to power and sustain a 16-bit embedded microcontroller for sensing and machine-to-machine applications without the use of batteries. In [17], the authors proposed a multiband $\mathrm{RF}$ energy harvesting system for three different operating frequencies, $900 \mathrm{MHz}, 1800 \mathrm{MHz}$, and $2.45 \mathrm{GHz}$. The proposed system can achieve 15\% more efficiency compared to single-frequency RF harvester. However, in [18], the RF energy harvesting system was designed based on planar dualband antenna at 900 and $2000 \mathrm{MHz}$ that can provide the required impedance matching to the RF chip at two bands and can be easily integrated with the RF harvester chip on the same circuit board. The authors in [19] proposed a prototype microstrip patch antenna to operate in the $2.4 \mathrm{GHz}$ ISM band in order to collect RF energy and charge a super capacitor to power a sensor node to $3.6 \mathrm{~V}$ in $27 \mathrm{~s}$ for structural health monitoring applications. A triple-band antenna for ambient RF energy harvesting system operating

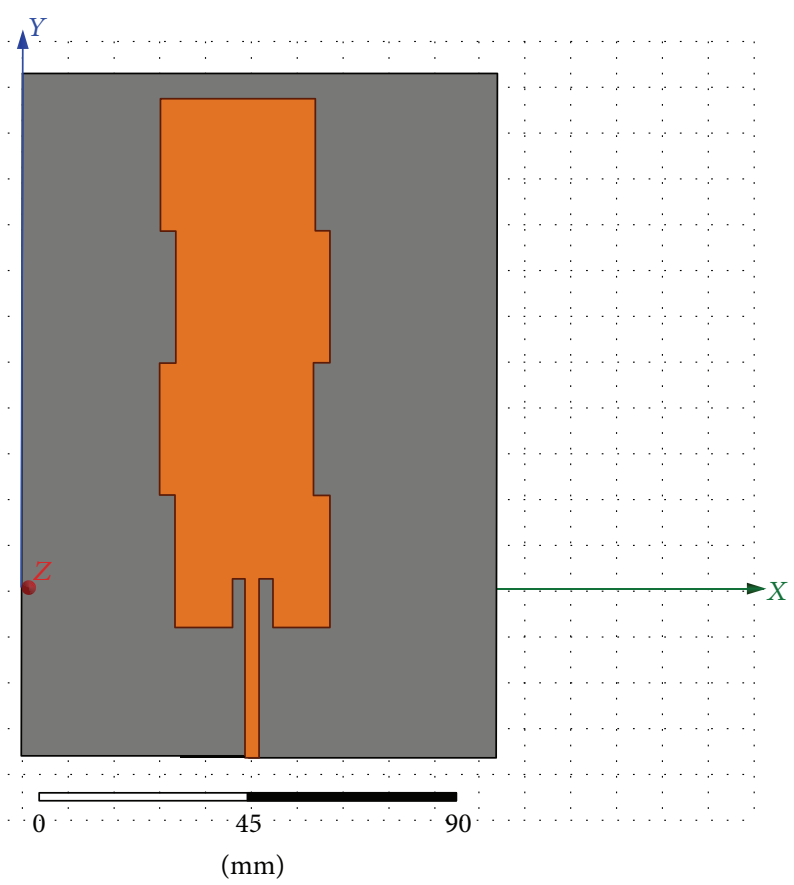

FIGURE 2: Geometry of the proposed dual-band antenna.

at $940 \mathrm{MHz}, 1.95 \mathrm{GHz}$, and $2.44 \mathrm{GHz}$ is designed in [20] with new technique for multiple-band matching of a rectifier to achieve high efficiency. The realized gain is $0.3 \mathrm{dBi}, 2.3 \mathrm{dBi}$, and $3.5 \mathrm{dBi}$, respectively, and the measured received power from harvesting RF energy at three bands simultaneously is 6.6 times more than that at single $900 \mathrm{MHz}$ band. Authors in [21] present a novel RF energy harvesting system for energizing the WSN. The novelty of the work is the use of the multiband microstrip crossed monopole antenna with circular polarization and impedance of $377 \Omega$. Achieved results show that the rectifying antenna system generates the desired voltage to energize the wireless sensor nodes. Table 2 summarizes the features of some energy harvesting antennas from various RF energy sources proposed in literature.

In this paper, a novel dual-band antenna is designed operating at $\mathrm{Wi}-\mathrm{Fi}$ bands $2.45 \mathrm{GHz}$ and $5 \mathrm{GHz}$ and is presented in order to harvest successfully RF power. Section 2 describes the proposed dual-band antenna considered for collecting RF energy. Section 3 discusses the measured results and the antenna performance. Finally, conclusions are drawn in Section 4.

\section{RF Energy Harvesting Antenna Design}

This section deals with the design of dual-band antenna for maximizing RF signal harvested. The simulated results and analysis for the energy harvesting antenna are discussed.

2.1. Antenna Design. The geometry of the proposed antenna is shown in Figure 2. The substrate material is RT/Duroid 5870 [26] as one of the popular industry-wide standard substrate material formats for electronic circuit boards. The 
TABLE 2: Overview of RF harvesting energy antenna.

\begin{tabular}{|c|c|c|c|c|c|}
\hline Type of antenna & Frequency & Maximum voltage & $\begin{array}{c}\text { Maximum } \\
\text { performance }\end{array}$ & Energy harvested & Reference \\
\hline $\begin{array}{l}\text { Folded patch antenna } \\
\text { Maximum power received is }-10 \mathrm{dBm}\end{array}$ & $2.4 \mathrm{GHz}$ & $\mathrm{n} / \mathrm{a}$ & $\mathrm{n} / \mathrm{a}$ & $373,248 \mu \mathrm{W}$ & {$[22]$} \\
\hline $\begin{array}{l}\text { Spiral antenna } \\
\text { Maximum power received is }-42 \mathrm{dBm}\end{array}$ & $2.4 \mathrm{GHz}$ & $\mathrm{n} / \mathrm{a}$ & $0.60 \%$ & $400 \mathrm{pW}$ & {$[23]$} \\
\hline Patch antenna & $500-700 \mathrm{MHz}$ & $134 \mathrm{mV}$ & $\begin{array}{c}18.2 \% \\
(\text { Pin }=-20 \mathrm{dBm})\end{array}$ & $\mathrm{n} / \mathrm{a}$ & {$[24]$} \\
\hline Loop antenna & $954 \mathrm{kHz}$ & $520 \mathrm{mV}$ & $\mathrm{n} / \mathrm{a}$ & $60.4 \mu \mathrm{J}$ & {$[25]$} \\
\hline
\end{tabular}

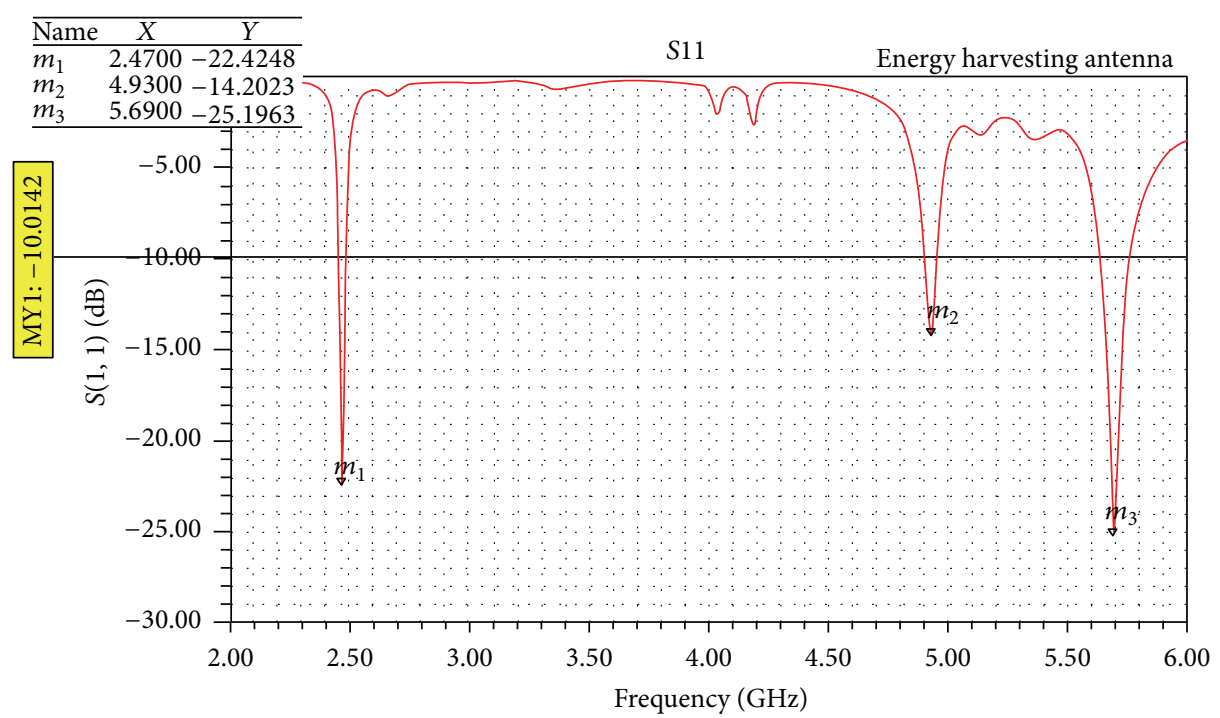

$$
\begin{aligned}
& \text { Curve info } \\
& \text { Setup1: sweep }
\end{aligned}
$$

FIgURE 3: Simulated return loss $S 11(\mathrm{~dB})$ versus frequency $(\mathrm{GHz})$.

key property of RT/Duroid 5870 relates to the dielectric permittivity constancy over a wide frequency range and its low dissipation factor that extends its usefulness to $\mathrm{Ku}$ band and above. The important specifications chosen in simulation for this design are as follows: the thickness of substrate, $1.6 \mathrm{~mm}$; the thickness of copper, $0.035 \mathrm{~mm}$; the relative permittivity, 2.33; and the loss tangent, 0.0012 . Duroid 5870 has lower loss tangent of 0.0012 compared to 0.02 for FR4. The antenna size is characterized by its length, width, and height $(L, W$, and $h)$ and is fed by feed line and is followed by a ground plane. The antenna is designed and optimized to capture the energy from the ambient at radio frequency range of Wi-Fi bands $2.45 \mathrm{GHz}$ and $5 \mathrm{GHz}$. The challenge is to design an antenna able to operate in both $2.4 \mathrm{GHz}$ band and $5 \mathrm{GHz}$ band. This antenna is highly desired also for the system flexibility.

The antenna design required the best choice of the substrate dielectric constant, length and width of the antenna, and the ground plane. The properties and performance of the proposed antenna have been predicted and optimized through electromagnetic simulation software in Ansoft HFSS environment. The size of the proposed RF energy harvester can be reduced by miniaturizing the antenna. An antenna is one of the few components, the size of which is related to the operating frequency. In general, microstrip antennas are halfwavelength structures, with a resonant frequency given by (1) [27], where $C$ is the speed of light, $L$ is the patch length of the antenna, and $\varepsilon_{r}$ is the relative permittivity of the grounded microwave substrate. The dielectric constant of the substrate has a considerable role in the antenna overall performance, the width, the length, and the resonant frequency. Consider

$$
f=\frac{C}{2 * L \sqrt{\varepsilon_{r}}} .
$$

2.2. Simulations Results. With the overall objective of RF efficient energy harvesting, we focused on the development, fabrication, and characterization of a dual-band antenna designed to serve as our receiving antenna. The reflection coefficient of the proposed antenna is measured between $1 \mathrm{GHz}$ and $6 \mathrm{GHz}$. The simulations result of the return loss (S11) is shown in Figure 3. From the result it is observed that the antenna is resonating at $2.47 \mathrm{GHz}, 4.93 \mathrm{GHz}$, and $5.69 \mathrm{GHz}$ with return loss below $14 \mathrm{~dB}$. 


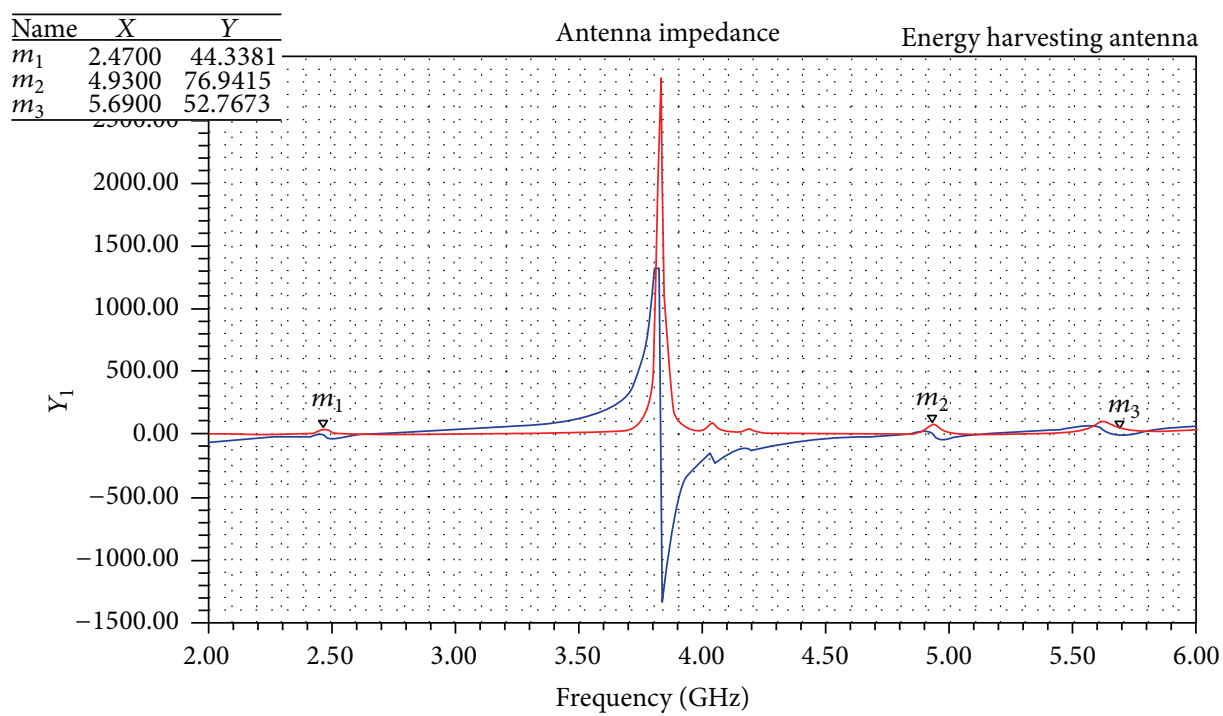

Curve info

$-\operatorname{im}(Z(1,1))$

$-\operatorname{re}(Z(1,1))$

Figure 4: Simulated input impedance of antenna.

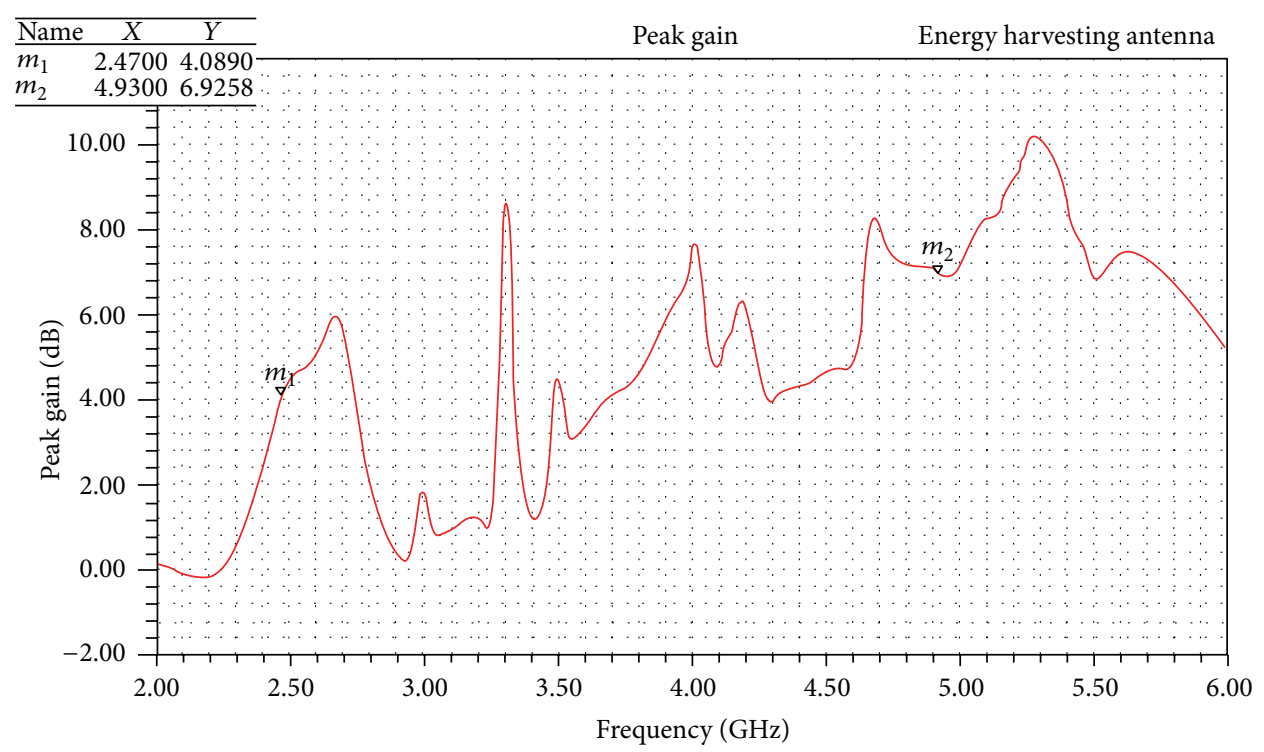

FIGURE 5: Peak gain of the proposed dual-band antenna.

The results of the simulated impedance are shown in Figure 4. The real part of the impedance at the resonant frequencies is close to $50 \Omega,\left(m_{1}\right) 44.33 \Omega$, and $\left(m_{3}\right) 52.76 \Omega$ for $2.4 \mathrm{GHz}$ and $5.69 \mathrm{GHz}$, respectively. The imaginary part of the impedance is almost negligible in the desired range of frequency band.

Figure 5 presents the peak gain of the proposed dualband antenna. In the $2.4 \mathrm{GHz}$ band, the peak gain is about $4 \mathrm{dBi}$, while in the $5 \mathrm{GHz}$ band the peak gain is around $7 \mathrm{dBi}$. A high antenna gain is also required to harvest as much wireless power as possible, especially in the case when the source location is known. The radiation characteristics of the proposed antenna as distributions of the energy radiated in the space are shown in Figure 6. The shape of radiation varies according to frequency; a quasi-omnidirectional radiation is obtained in $2.4 \mathrm{GHz}$ and $5 \mathrm{GHz}$ frequencies. Therefore, the antenna designed is very interesting for a system of wireless energy harvesting, meeting the desired criteria to maximize the captured RF energy.

The results obtained are very interesting and indicate clearly that the proposed antenna is capable of providing good performances in terms of return loss, gain, and radiation 


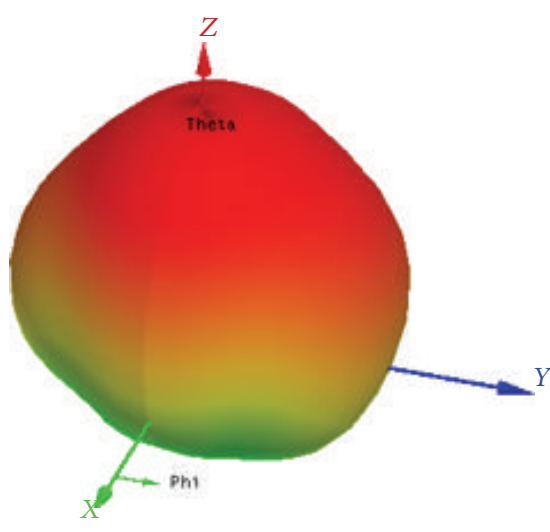

(a)

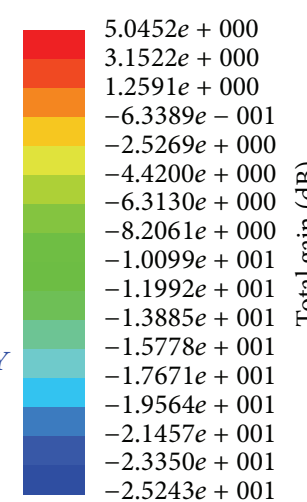

$-2.5243 e+001$

FIGURE 6: 3D radiation pattern of the antenna at $2.4 \mathrm{GHz}$ (a) and $5 \mathrm{GHz}$ (b).
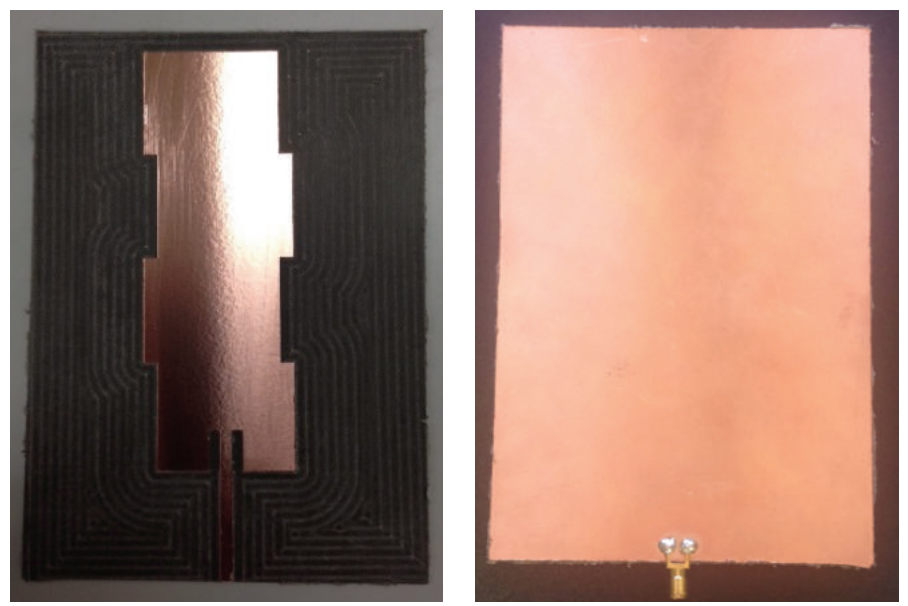

FIGURE 7: Photograph of proposed antenna (fabricated prototype).

pattern. Experimental tests in order to characterize the performance of the proposed antenna will be discussed in Section 3.

\section{Fabrication and Evaluation}

3.1. Measured Results. The fundamental objective of this research has been to develop a receiving antenna for wireless energy harvesting for the purpose of powering the wireless sensor networks. In order to validate the simulated results, a prototype of the proposed antenna was implemented and fabricated on RT/Duroid 5870 substrate $\left(\varepsilon_{r}=2.33, \tan \sigma=\right.$ 0.0012 ). Figure 7 shows the prototype antenna realized. The return loss was measured using a Rohde and Schwarz ZVA 24 Vector Network Analyzer and the radiation patterns were tested in the anechoic chambers at the Research Center of Polytechnic University of Valencia.

Several experimental studies were conducted as part of this research. The first series of experiments were conducted in the laboratory and were designed to compare the performance of our prototype antenna with the simulations results.

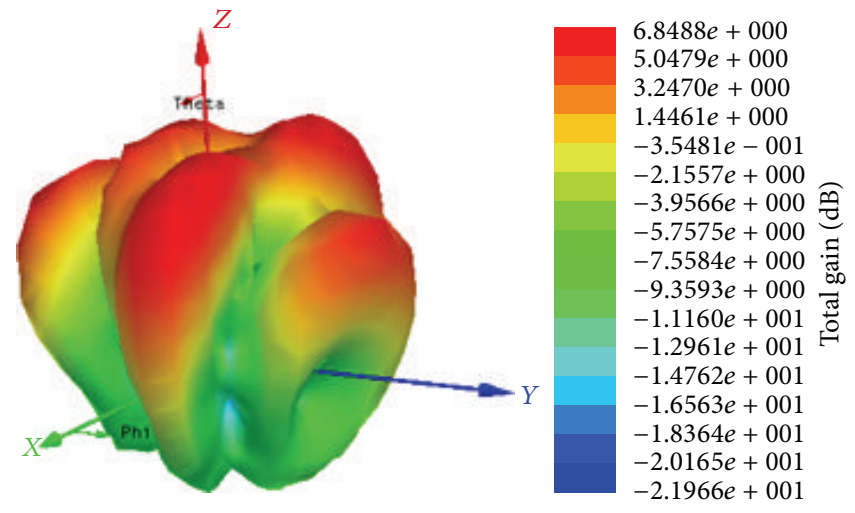

(b)

$-2.1966 e+001$ 


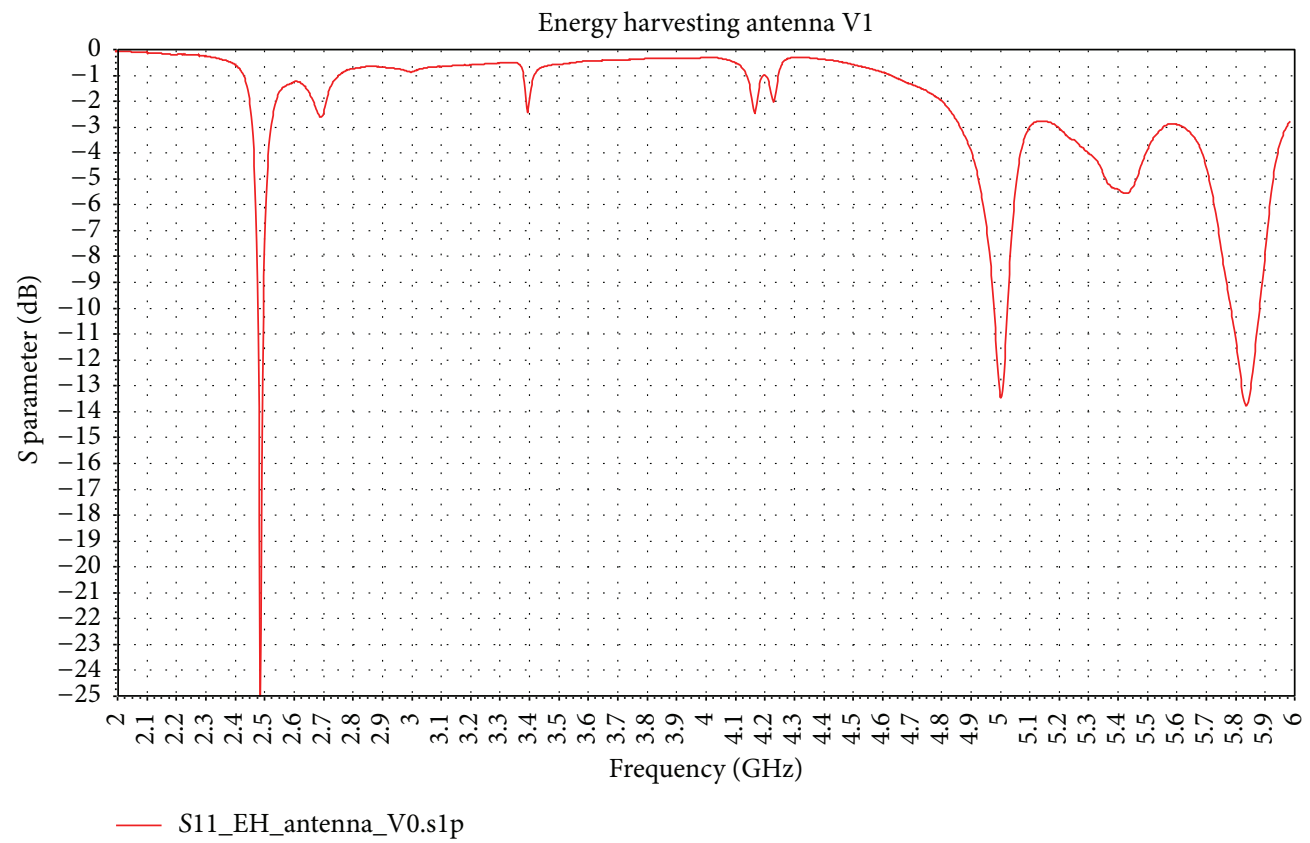

Figure 8: Measured return loss (dB).

Total electric field 3D $(\mathrm{dB})$

Maximum position: $\theta=90.00^{\circ}$ y $\varphi=177.00^{\circ}$

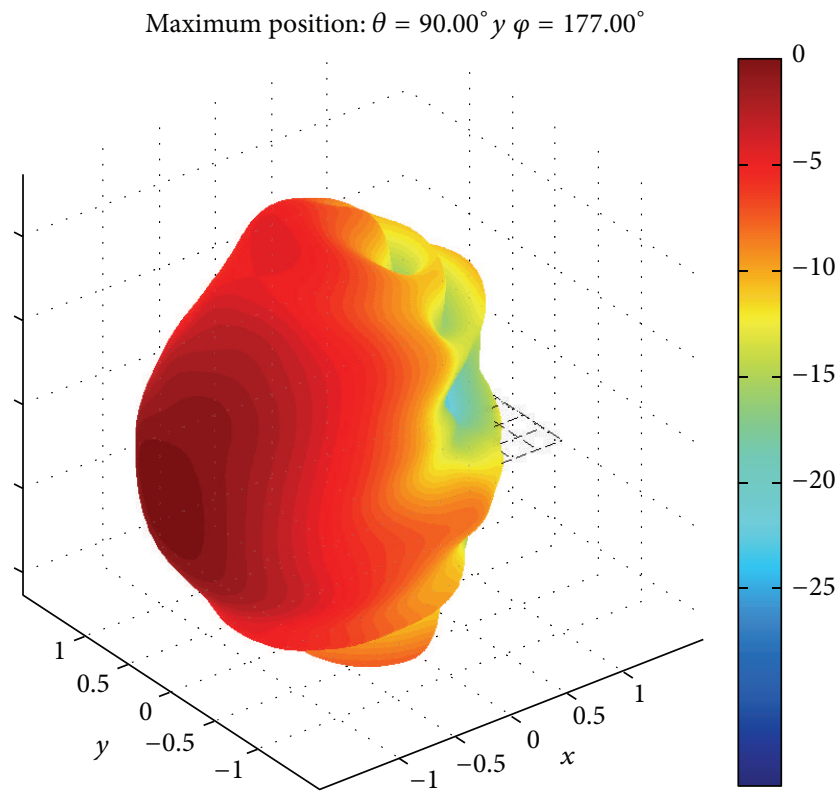

$2.48 \mathrm{GHz}$
Total electric field $3 \mathrm{D}(\mathrm{dB})$

Maximum position: $\theta=90.00^{\circ} y \varphi=133.00^{\circ}$

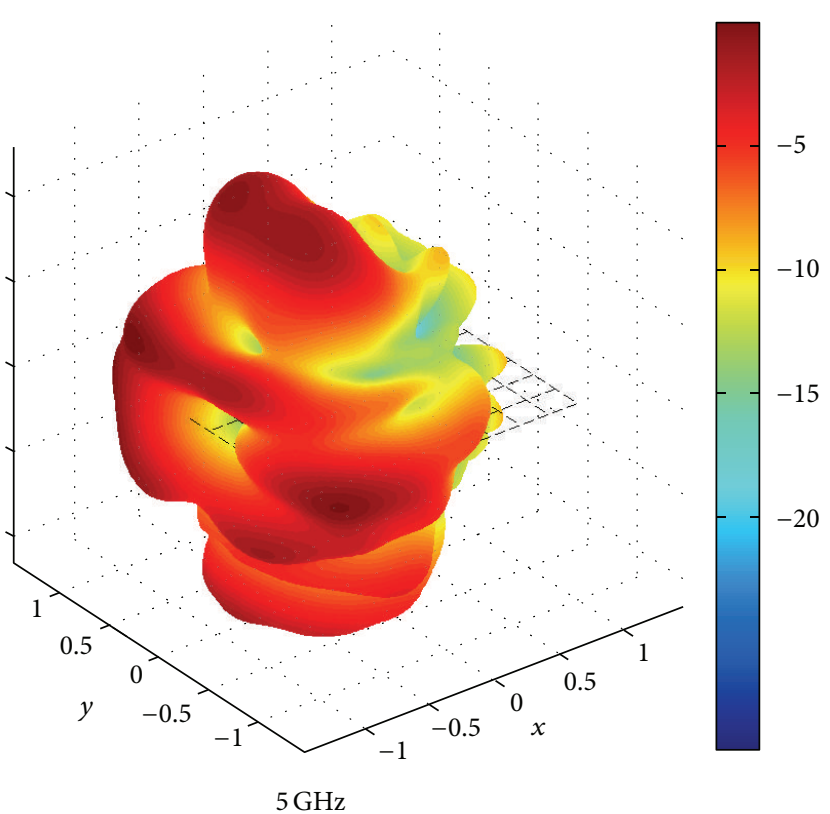

FIgURE 9: Total electric field of the dual-band antenna at $2.4 \mathrm{GHz}$ and $5 \mathrm{GHz}$.

module for the proposed RF energy harvesting system is shown in Figure 10. The diodes used are SMS7630-079LF RF Schottky Diodes and capacitors of $1.8 \mathrm{nF}$ in terms of capacity. These diodes are low substrate losses and have low forward voltage, very fast switching and have been modeled for energy harvesting circuits.

Printed circuit board (PCB) was manufactured on FR 4 substrate with thickness of $1.6 \mathrm{~mm}$ and dielectric constant of
3.9. Photograph of two assembled circuit board is shown in Figure 11. The circuit is performed with the dimensions of $71.6 \mathrm{~mm} \times 12 \mathrm{~mm}$. The main objective is to maximize the DC energy harvested by recovering all Wi-Fi signals available. The overall RF energy harvesting system is designed for energizing low power devices. Measurements are performed under real conditions by using an intentional radio frequency signal source from the Signal Generator R\&S SMIQ 04B and 


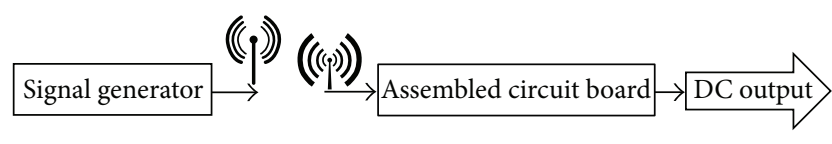

FIGURE 10: Measurements protocol.

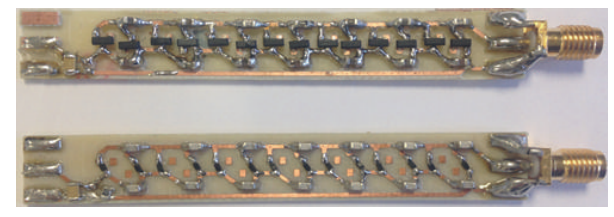

FIGURE 11: Prototypes of the assembled circuit board of 7-stage voltage doubler.

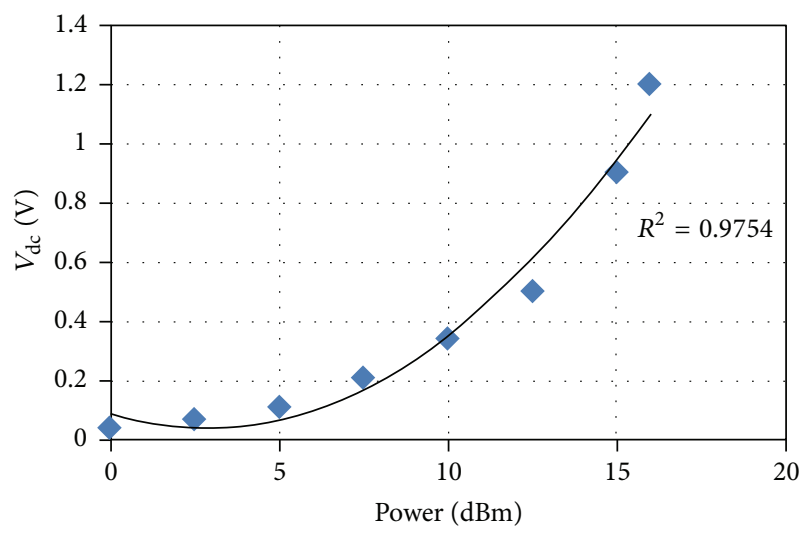

FIGURE 12: Results of test for DC output of proposed system versus input power at a distance of $170 \mathrm{~cm}$.

a transmission directional antenna operating in $2.4-2.5 \mathrm{GHz}$ with gain of $14 \mathrm{dBi}$. The test results of the DC output voltage obtained as a function of the signal generator power are shown in Figure 12.

The voltage output decreases with the distance between the transmission antenna and the harvesting energy system as illustrated in Figure 13. The system produces DC output voltage of $1.3 \mathrm{~V}$ at $10 \mathrm{dBm}$ and a distance of $60 \mathrm{~cm}$ from the signal generator.

\section{Conclusion}

RF energy harvesting is a key technology due to its potential to provide power indefinitely. It is a green technology suitable for a wide range of wireless applications such as RFID tags, implantable electronics devices, and wireless sensor networks. In this paper, a novel receiving antenna capable of dual-band operation has been proposed for RF energy harvesting system. A dual-band with wide bandwidth characteristics is observed which covers Wi-Fi bands. The results obtained indicate a good overall performance of the proposed antenna at the required frequency range: return loss better than $20 \mathrm{~dB}$ with impedance close to $50 \Omega$ and quasi-omnidirectional radiation patterns. Good agreements are achieved between the simulated and measured results that

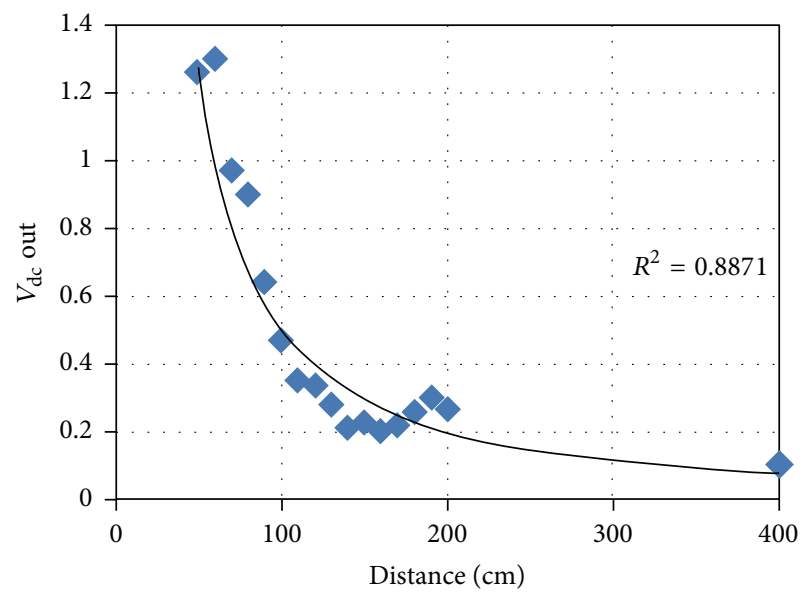

FIGURE 13: DC output of proposed system versus the distance for a power of $10 \mathrm{dBm}$.

satisfy the end application requirement. Based on the results achieved the current work consists in improving the antenna performances in order to cover completely the required bandwidths of IEEE $802.11 \mathrm{~b} / \mathrm{g}$ and IEEE 802.11a. The patch antenna is especially suitable for narrow bandwidth applications. Therefore, the challenge is to expand the bandwidth in order to make the antenna for wideband energy harvesting environment.

\section{Conflict of Interests}

The authors declare that there is no conflict of interests regarding the publication of this paper.

\section{Acknowledgments}

This work was supported in part by EMMAG Program 2014. The tests have been performed under the collaboration with the Electromagnetic Radiation Laboratory (GRE Lab) of the UPV.

\section{References}

[1] S. Chalasani and J. M. Conrad, "A survey of energy harvesting sources for embedded systems," in Proceedings of the IEEE Southeastcon, pp. 442-447, IEEE, Huntsville, Ala, USA, April 2008.

[2] S. Sudevalayam and P. Kulkarni, "Energy harvesting sensor nodes: survey and implications," IEEE Communications Surveys \& Tutorials, vol. 13, no. 3, pp. 443-461, 2011.

[3] L. Mateu, C. Codrea, N. Lucas, M. Pollak, and P. Spies, "Energy harvesting for wireless communication systems using thermogenerators," in Proceedings of the 21st Conference on Design of Circuits and Integrated Systems (DCIS '06), Barcelona, Spain, November 2006.

[4] H. Böttner, J. Nurnus, A. Gavrikov et al., "New thermoelectric components using microsystem technologies," Journal of Microelectromechanical Systems, vol. 13, no. 3, pp. 414-420, 2004.

[5] Y. K. Tan, K. Y. Hoe, and S. K. Panda, "Energy harvesting using piezoelectric igniter for self-powered radio frequency 
(RF) wireless sensors," in Proceedings of the IEEE International Conference on Industrial Technology (ICIT '06), pp. 1711-1716, Mumbai, India, December 2006.

[6] A. Hande, T. Polk, W. Walker, and D. Bhatia, "Indoor solar energy harvesting for sensor network router nodes," Microprocessors and Microsystems, vol. 31, no. 6, pp. 420-432, 2007.

[7] C. Alippi and C. Galperti, "An adaptive system for optimal solar energy harvesting in wireless sensor network nodes," IEEE Transactions on Circuits and Systems, vol. 55, no. 6, pp. 17421750, 2008.

[8] L. M. Borges, N. Barroca, H. M. Saraiva et al., "Design and evaluation of multi-band RF energy harvesting circuits and antennas for WSNs," in Proceedings of the 21st IEEE International Conference on Telecommunications, pp. 308-312, Lisbon, Portugal, May 2014.

[9] M. Ali, L. Albasha, and N. Qaddoumi, "RF energy harvesting for autonomous wireless sensor networks," in Proceedings of the 8th International Conference on Design \& Technology of Integrated Systems in Nanoscale Era (DTIS '13), pp. 78-81, IEEE, Abu Dhabi, United Arab Emirates, March 2013.

[10] T. Sogorb, J. Vicente Llario, J. Pelegri, R. Lajara, and J. Alberola, "Studying the feasibility of energy harvesting from broadcast RF station for WSN," in Proceedings of the IEEE Instrumentation and Measurement Technology Conference Proceedings (IMTC '08), pp. 1360-1363, IEEE, Victoria, Canada, May 2008.

[11] T. S. Salter, Low power smartdust receiver with novel applications and improvements of an RF power harvesting circuit [Ph.D. thesis], University of Maryland, 2009.

[12] C. Mikeka and H. Arai, "Sustainable energy harvesting technologies-past, present and future," in Design Issues in Radio Frequency Energy Harvesting System, Y. K. Tan, Ed., InTech, Vienna, Austria, 2011.

[13] T. B. Lim, N. M. Lee, and B. K. Poh, "Feasibility study on ambient RF energy harvesting for wireless sensor network," in Proceedings of the IEEE MTT-S International Microwave Workshop Series on RF and Wireless Tecbhnologies for Biomedical and Healthcare Applications (IMWS-BIO '13), pp. 1-3, IEEE, Singapore, December 2013.

[14] P. Nintanavongsa, U. Muncuk, D. R. Lewis, and K. R. Chowdhury, "Design optimization and implementation for RF energy harvesting circuits," IEEE Journal on Emerging and Selected Topics in Circuits and Systems, vol. 2, no. 1, pp. 24-33, 2012.

[15] A. Al-Khayari, H. Al-Khayari, S. Al-Nabhani, M. M. BaitSuwailam, and Z. Nadir, "Design of an enhanced RF energy harvesting system for wireless sensors," in Proceedings of the 7th IEEE GCC Conference and Exhibition (GCC '13), pp. 479-482, Doha, Qatar, November 2013.

[16] R. J. Vyas, B. B. Cook, Y. Kawahara, and M. M. Tentzeris, "E-WEHP: a batteryless embedded sensor-platform wirelessly powered from ambient digital-TV signals," IEEE Transactions on Microwave Theory and Techniques, vol. 61, no. 6, pp. 24912505, 2013.

[17] S. Keyrouz, H. J. Visser, and A. G. Tijhuis, "Multi-band simultaneous radio frequency energy harvesting," in Proceedings of the 7th European Conference on Antennas and Propagation (EuCAP '13), pp. 3058-3061, IEEE, Gothenburg, Sweden, April 2013.

[18] X. Shao, B. Li, N. Shahshahan, N. Goldsman, T. S. Salter, and G. M. Metze, "A planar dual-band antenna design for RF energy harvesting applications," in Proceedings of the International Semiconductor Device Research Symposium (ISDRS '11), pp. 1-2, IEEE, College Park, Md, USA, December 2011.
[19] K. M. Farinholt, G. Park, and C. R. Farrar, "RF energy transmission for a low-power wireless impedance sensor node," IEEE Sensors Journal, vol. 9, no. 7, pp. 793-800, 2009.

[20] B. L. Pham and A.-V. Pham, "Triple bands antenna and high efficiency rectifier design for RF energy harvesting at 900, 1900 and $2400 \mathrm{MHz}$," in Proceedings of the IEEE MTT-S International Microwave Symposium Digest (MTT '13), Seattle, Wash, USA, June 2013.

[21] S. Ghosh, S. K. Ghosh, and A. Chakrabarty, "Design of RF energy harvesting system for wireless sensor node using circularly polarized monopole antenna: RF energy harvesting system for WSN node using circularly polarized antenna," in Proceedings of the 9th International Conference on Industrial and Information Systems (ICIIS '14), pp. 1-6, IEEE, Gwalior, India, December 2014.

[22] S. A. Bhalerao, A. V. Chaudhary, R. B. Deshmukh, and R. M. Patrikar, "Powering wireless sensor nodes using ambient RF energy," in Proceedings of the IEEE International Conference on Systems, Man and Cybernetics, pp. 2695-2700, Taipei, Taiwan, October 2006.

[23] D. Bouchouicha, F. Dupont, M. Latrach, and L. Ventura, "Ambient RF energy harvesting," in Proceedings of the International Conference on Renewable Energies and Power Quality (ICREPQ '10), Granada, Spain, March 2010.

[24] C. Mikeka, H. Arai, A. Georgiadis, and A. Collado, "DTV band micropower RF energy-harvesting circuit architecture and performance analysis," in Proceedings of the IEEE International Conference on RFID-Technologies and Applications (RFID-TA '11), pp. 561-567, Sitges, Spain, September 2011.

[25] M. Muramatsu and H. Koizumi, "An experimental result using RF energy harvesting circuit with dickson charge pump," in Proceedings of the IEEE International Conference on Sustainable Energy Technologies (ICSET '10), Kandy, Sri Lanka, December 2010.

[26] Rogers Corporation, [RT-Duroid]:RT-Duroid-5870-5880-DataSheet, Rogers Corporation, Rogers, Conn, USA, 2011.

[27] K.-L. Wong, Compact and Broadband Microstrip Antennas, Wiley-Interscience, 2002.

[28] N. M. Din, C. K. Chakrabarty, A. Bin Ismail, K. K. A. Devi, and W.-Y. Chen, "Design of RF energy harvesting system for energizing low power devices," Progress in Electromagnetics Research, vol. 132, pp. 49-69, 2012. 


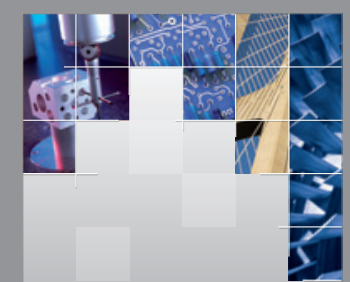

\section{Enfincering}
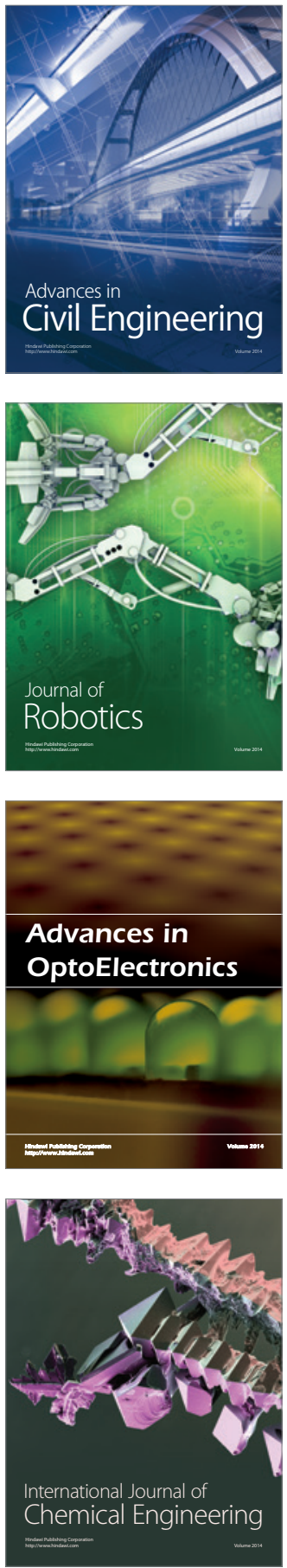

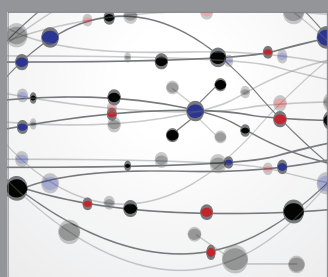

The Scientific World Journal

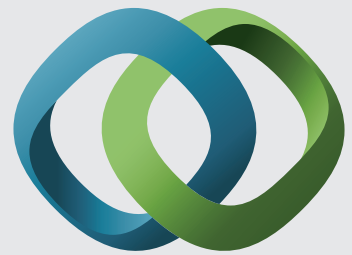

\section{Hindawi}

Submit your manuscripts at

http://www.hindawi.com
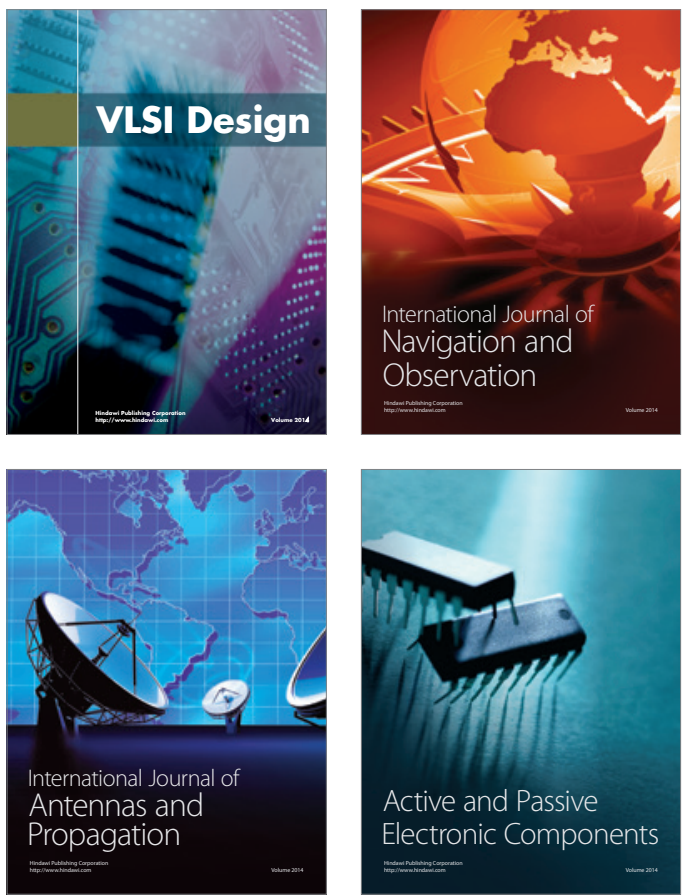
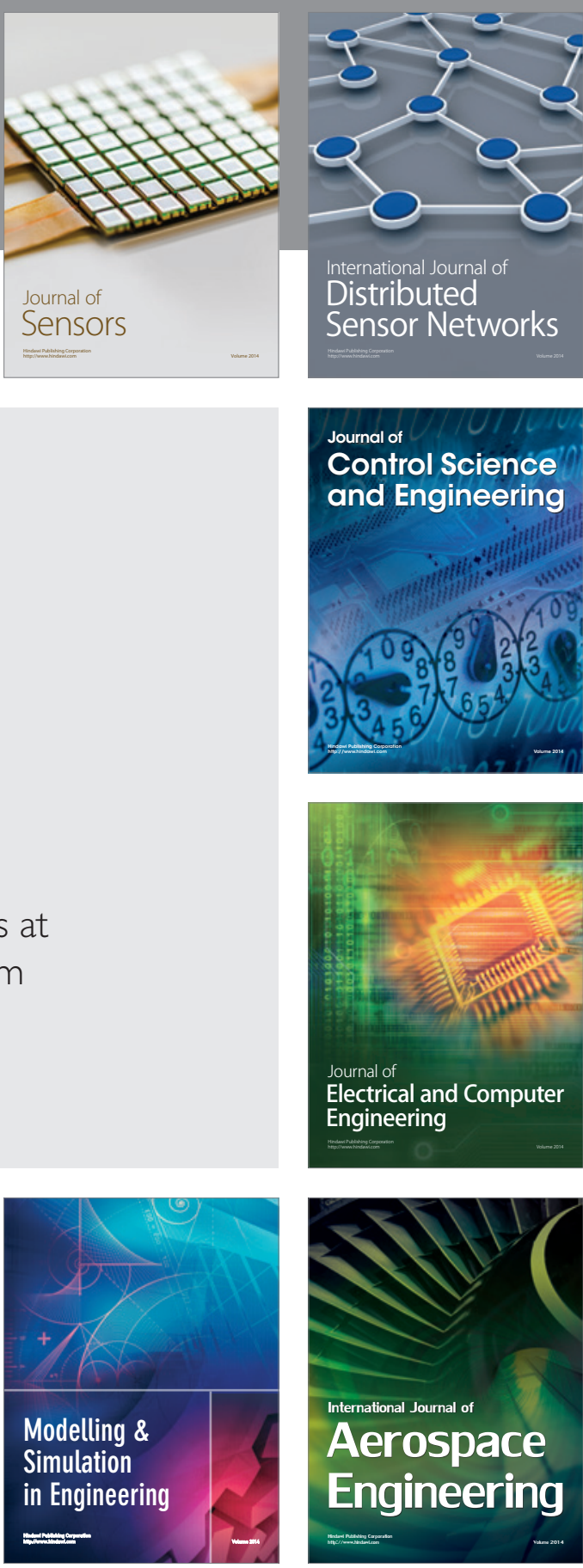

International Journal of

Distributed

Sensor Networks

Journal of

Control Science

and Engineering
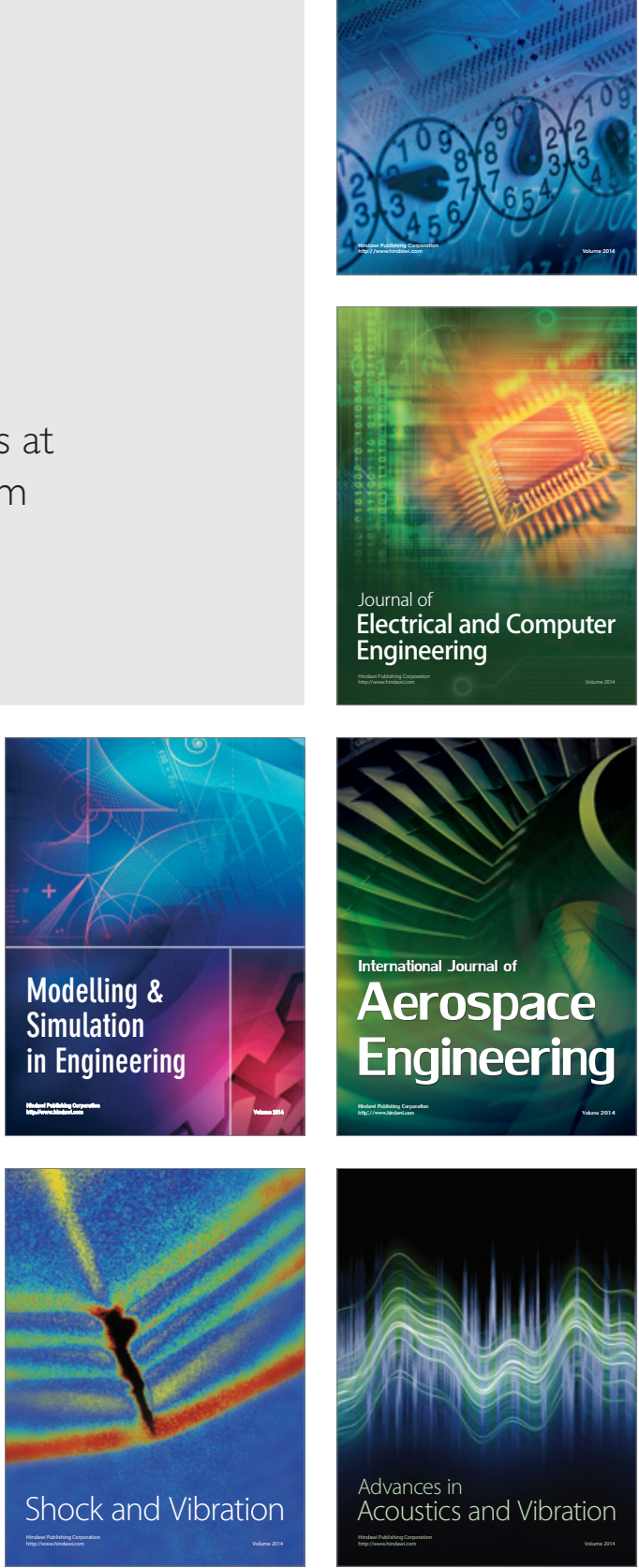